
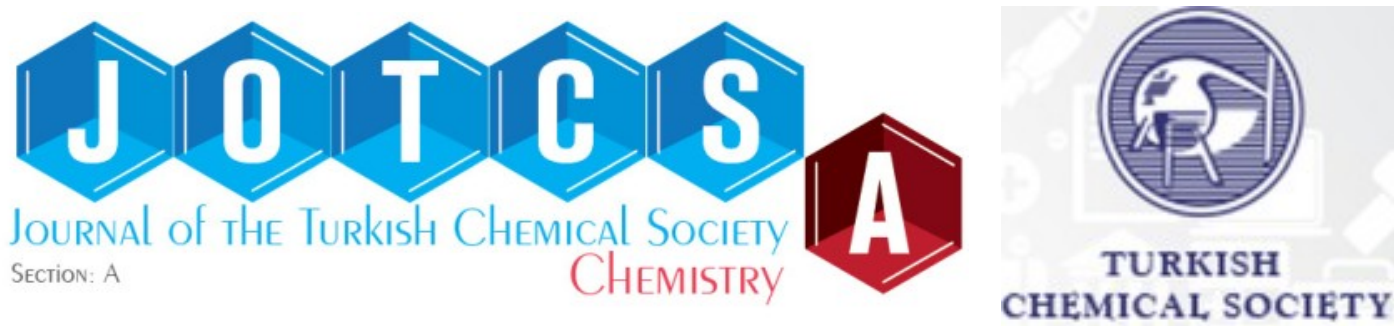

\title{
Evaluation of PVA/Chitosan Cryogels as Potential Tissue Engineering Scaffolds; Synthesis, Cytotoxicity, and Genotoxicity Investigations
}

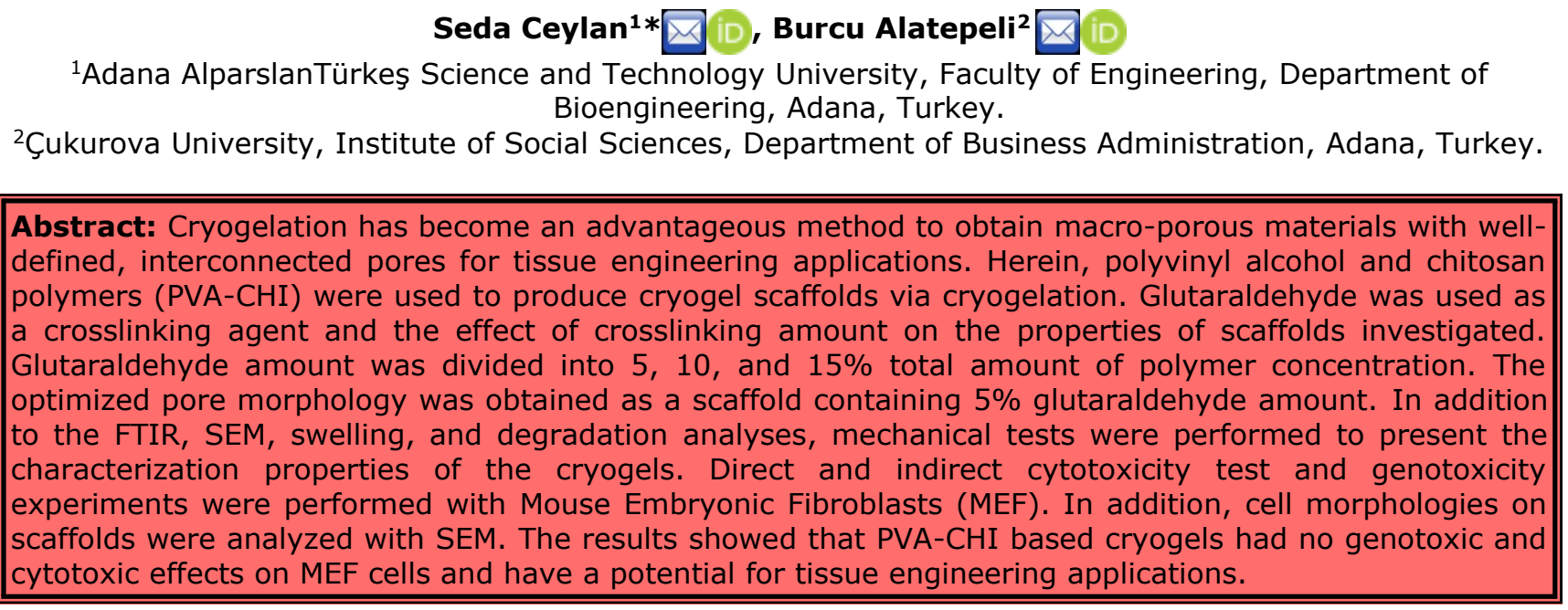

Keywords:Polymeric scaffolds, PVA, chitosan, cryogel, genotoxicity.

Submitted: August 25, 2020. Accepted: November 17, 2020.

Cite this: Ceylan S, Alatepeli B. Evaluation of PVA/Chitosan Cryogels as Potential Tissue Engineering Scaffolds; Synthesis, Cytotoxicity, and Genotoxicity Investigations. JOTCSA. 2021;8(1):69-78.

DOI: https://doi.org/10.18596/jotcsa.825115.

*Corresponding author. E-mail: sceylan@atu.edu.tr.

\section{INTRODUCTION}

Tissues have regeneration capacity, but large defects need grafts such as autografts, allografts, xenografts, and synthetic grafts to treat the restoration of tissue (1). Autografts, allografts, and xenografts have some problems, including the infection, pain, and immune rejection. In order to solve these problems, tissue engineers purpose to produce implantable synthetic grafts in laboratory conditions by using synthetic materials. In other words, tissue engineering aims to regenerate injured tissues by combining porous scaffold biomaterials with cells and body/growth factors, which act as a mold for tissue regeneration $(2,3)$. Consequently, in recent years biodegradable polymeric grafts/scaffolds have been gained a great interest in tissue regeneration. In fact, these scaffolds are biocompatible substrates for cell growth, adhesion, proliferation, and formation of the new tissue in defected areas $(4,5)$. Both natural and synthetic polymers have been broadly utilized in different tissue engineering applications $(6,7)$. Synthetic polymers can be tailored easily and have predictable properties. Moreover, natural polymers do not cause an immune reaction or inflammation. In addition, natural polymers are biocompatible and bioabsorbent (8). The main aim of blending natural and synthetic polymers is to fabricate ideal scaffolds for various tissue engineering applications.

In this work, synthetic polyvinyl alcohol (PVA) and natural chitosan ( $\mathrm{CHI}$ ) polymers were used to produce porous scaffolds. Glutaraldehyde (GA) was used as a crosslinking agent. GA amount is an important parameter for scaffold productions. There are several researches about the amount of GA. In addition, in several researches GA was used to produce scaffold and in vitro and in vivo experiments results show that produced scaffolds by 
GA crosslinking agent supports cell viability and proliferation (9-12). PVA is a biodegradable polymer used in tissue engineering due to its biodegradability, crystallinity, and mechanical properties. PVA can be blended with starch, gelatin, polycaprolactone (PCL), and $\mathrm{CHI}$ to increase its biodegradability and biocompatibility (13-16). CHI is a non-toxic, biodegradable, and biocompatible polymer and has been extensively studied in the design of many different types of tissue engineering applications (17). Up to this time, different production techniques have been used such as electrospinning, freeze-thawing and solution casting, etc. to produce PVA / CHI scaffolds (1820). Cryogelation is another technique to fabricate scaffolds with interconnected pores at sub-zero temperatures. The interconnected macropores are important for scaffold design because this property allows diffusion of solutes and mass transportation of micro and nanoparticles. The scaffolds fabricated by the cryogelation technique show a high degree of mechanical stability. In addition to this property, they represent high resistance to deformations such as torsion and elongation (21). Characteristic properties of cryogel scaffolds can be adjusted by freezing temperature, thawing period, polymer concentration, and crosslinking amount.

The aim of this study is to produce PVA / CHI porous cryogel scaffolds at subzero temperatures for the potential of different tissue engineering applications. In the literature, although there are different articles about PVA and CHI - based cryogels, to the best of authors' knowledge, there is no scientific study about the genotoxicity properties of scaffolds and comparison of those scaffolds' mechanical properties, in terms of using different crosslinking amount (GA) to fabricate them. The chemical composition of PVA / CHI cryogels was characterized by Fourier transform infrared analyses. In addition, water uptake, degradation, and mechanical properties were investigated. Indirect and direct cytotoxicity tests, cell morphology investigations, and genotoxicity studies were also analyzed with mouse embryonic fibroblast (MEF) cell line.

\section{MATERIAL and METHODS}

\section{Chemicals}

Polyvinyl alcohol with a molecular weight of 89,000$98,000 \mathrm{~g} \mathrm{~mol}^{-1}$ (99\% hydrolyzed) and chitosan (low molecular weight) were obtained from SigmaAldrich (USA). Glutaraldehyde (25\% (v/v), aqueous) was purchased from Merck (Germany).

\section{Preparation of PVA-CHI Scaffolds}

CHI solution ( $1 \% \mathrm{w} / \mathrm{v}$ ) was prepared by dissolving 1 $\mathrm{g}$ of low molecular weight chitosan in $100 \mathrm{~mL}$ of $3 \%$ acetic acid solution under magnetic stirring and left for 6 hours for complete dissolution. $5 \%(\mathrm{w} / \mathrm{v})$ of PVA was dissolved in deionized water at $90^{\circ} \mathrm{C}$ with continuous mechanical stirring for 3 hours. PVA and $\mathrm{CHI}$ solutions were mixed in fixed amounts to obtain mixtures having $\mathrm{CHI}$ : PVA volume ratios of $1: 1$. Glutaraldehyde (GA, 5, 10, and $15 \%$ weight of total polymer amount) was slowly added to the mixtures under constant stirring. The detailed composition (w/w) of the cryogels and GA amount are listed in Table 1. After that, the solutions were put into the cryostat at $-10{ }^{\circ} \mathrm{C}$ and allowed to undergo cryogelation for $4 \mathrm{~h}$ (Wisd Laboratory Instrument, WiseCircu WCR-P6, Korea). By this time, the color of the gels turned to yellow. The cryogels were transferred to the freezer at $-16^{\circ} \mathrm{C}$ and incubated for $20 \mathrm{~h}$ in the freezer. After the cryogelation period was finished, the cryogels were allowed to reach the room temperature to thaw for $1 \mathrm{~h}$, and cryogels were immersed in deionized water to remove unreacted GA and polymer. Washing procedure continued for 6 hours and water was changed several times. All cryogels were freeze-dried (FreeZoneBenchtop Freeze DrySystem-7670531, Labconco, USA) before performing characterization investigations.

Table 1.Quantities of PVA and chitosan (w:w) used in the preparation scaffolds.

\begin{tabular}{|l|l|l|l|}
\hline Scaffold Code & PVA & Chitosan & GA \\
\hline PVA-CHI (GA) 5 & $83 \%$ & $17 \%$ & $5 \%$ \\
\hline PVA-CHI (GA) 10 & $83 \%$ & $17 \%$ & $10 \%$ \\
\hline PVA-CHI (GA) 15 & $83 \%$ & $17 \%$ & $15 \%$ \\
\hline
\end{tabular}

\section{FTIR Instrumentation}

Chemical analysis of the cryogels has been performed by using FTIR (PerkinElmer, FTIR/FIR/NIR Spectrometer Frontier-ATR, and USA). Each scaffold was scanned in the frequency region of 400 to $4000 \mathrm{~cm}^{-1}$ using and the characteristic peaks of IR transmission spectra were recorded.

\section{SEM Instrumentation}

Scanning Electron Microscopy (FE-SEM Zeiss/Supra55, Quanta 400F Field Emission, USA) was used to analyze the surface morphology of cryogels. Samples were coated with a thin layer of platinum. SEM was used at the acceleration of $5 \mathrm{kV}$ and the magnification was $250 x$.

\section{Swelling Ratio}

The swelling ratio (SR\%) of cryogels was determined in phosphate buffer saline (PBS) at 37 ${ }^{\circ} \mathrm{C}$. The swelling ratio/water absorption capacity of the produced cryogels was calculated using Eq. 1. In order to calculate the average swelling ratio, three samples $(0.5 \mathrm{~cm}$ height and $0.9 \mathrm{~cm}$ diameter) were used. Firstly, dry weights of cryogels were recorded. 
Then, cryogels were immersed into deionized water. At certain times, the excess water from the surface of the cryogels was removed with filter paper and then cryogels were weighed. At different time intervals, this process was repeated and water uptake capacity of cryogels was calculated with respect to time. The swelling ratio/capacity of the cryogels was calculated using the equation below;

$$
S R(\%)=\left[\frac{(M f-M i)}{M i}\right] \times 100
$$

Where $\mathrm{Mi}$ is the initial dry weight of cryogel, Mf is the swollen weight of cryogel and SR is the swelling ratio.

\section{Degradation Ratio}

The weight loss or degradation ratio of cryogels was calculated using Eq. 2 . Three scaffolds $(0.5 \mathrm{~cm}$ height and $0.9 \mathrm{~cm}$ diameter) were used to investigate average weight loss.

The first step is weighing and recording dry cryogels. After that, cryogels were put into $15 \mathrm{~mL}$ tubes filled with PBS. The tubes were placed in water bath of which the temperature was adjusted to $37^{\circ} \mathrm{C}$ (Daihan Scientific Co. Ltd., WiseBath WB22 , Korea). At certain times, cryogels were dried at room temperature and weighed. Finally, the weight loss of the cryogels was calculated by the equation below:

$$
D D(\%)=\left[\frac{(W i-W f)}{W i}\right] \times 100
$$

Where $\mathrm{Wi}$ is the initial dry weight of cryogel, Wf is the final dry weight of cryogel, and DD is the degree of degradation or degradation rate(15).

\section{Mechanical Test}

The compression measurement of scaffolds was investigated using a texture analyzer (TA.XT. Plus Texture Analyzer, Stable Micro Systems, Surrey, UK). The cylindrical cryogels $(r=1 \mathrm{~cm}, \mathrm{~h}=0.5 \mathrm{~cm})$ were put into the surface of the analyzer. After that, compression speed was adjusted $0.1 \mathrm{~mm} \mathrm{~s}^{-1}$ and the compression force was analyzed by a $5 \mathrm{~kg}$ load cell. The gels were compressed $2 \mathrm{~mm}$ in a longitudinal direction after having achieved a trigger load of $1 \mathrm{~g}$. The compression tests of cryogels were performed at room temperature (22). Three samples were used to investigate the mechanical properties of cryogels.

\section{Cells and Culture Conditions}

Tests were carried out with mouse embryonic fibroblastic (CF-1), (ATCC1SCRC-1040 $\left.{ }^{\mathrm{TM}}\right)$, (MEF) cell line. The MEF cells were obtained from Professor Devrim Gozuacik (Department of Molecular Biology Genetics and Bioengineering, Sabanci University,
Istanbul, Turkey). The cell line cultured with high glucose Dulbecco's Modified Eagle's medium (DMEM, Lonza, Belgium) added with $10 \%$ fetal bovine serum (FBS, Lonza) and $55 \mu \mathrm{M} \beta$-mercaptoethanol (Merck, Germany) in a humidified incubator (NUAIRE, NU5800, USA) at $37^{\circ} \mathrm{C}$ in which the $\mathrm{CO}_{2}$ level was kept constant at $5 \%$.

\section{Direct \& Indirect Cytotoxicity Studies}

Sterilization of the scaffolds was performed by using $70 \%$ alcoholic solution and then washed 3 times with PBS. After that, the culture medium was used to wash scaffolds. Scaffolds were prepared at the same shape/volume $(r=6 \mathrm{~mm}, \mathrm{~h}=1 \mathrm{~mm})$ and transferred to the wells of a 6 -well flat culture plate for the direct cytotoxicity assay. The cells were drop-seeded over the surface of the scaffolds at a density of $2,5 \times 10^{5}$ cells $/ 10 \mu \mathrm{L}$. Meanwhile, as the control group, cells were drop-seeded into the 6well flat culture plate at the same density for per well. The cultures were incubated for 1,3 and 5 days. After this period, cell viabilities were examined by MTT protocol.

For the indirect assay, 25,000, 15,000, and 10,000 MEF cells per well were seeded into the 24-well plates. Control and test groups incubated with different media. The control group was incubated with normal medium (DMEM + 10\% FBS + and 55 $\mu \mathrm{M} \beta$-mercaptoethanol) and the test group was incubated with the medium which was designed with scaffold (scaffold degradation products with the medium).

For the 1 day incubation, 25,000 cells; 3 day incubation, 15,000 cells; and 5 day incubation 10,000 cells were transferred into the well at $37^{\circ} \mathrm{C}$ in a humidified $5 \% \quad \mathrm{CO}_{2}$ incubator. After the incubation period, the viabilities of cells were analyzed by MTT assay.

The first step of MTT assay was aspirating the culture medium and adding $1000 \mu \mathrm{L}$ MTT solution $(0,25 \mathrm{mg} / \mathrm{mL})$ into each well. Then, the plates were incubated for 2 hours at $37^{\circ} \mathrm{C}$ until the purple formazan crystals were formed. The second step was removing the medium and adding $1000 \mu \mathrm{L}$ isopropanol (Merck, Germany) to each well to dissolve the formazan crystals. Plates were agitated for 30 minutes.

A spectrophotometer (Shimadzu UV-VIS, UVmini1240, Japan) was used at $570 \mathrm{~nm}$ to read the dissolved formazan crystals of each well. Assays were processed in triplicate and cell viabilities were calculated with respect to the control groups.

\section{Cell Morphology Analysis}

For SEM measurement, MEF cells were seeded on scaffolds in six-well plates with $5 \times 10^{4}$ cells/well. After 5 days of incubation, the culture medium was aspirated and cells were fixed with $2.5 \%$ 
glutaraldehyde for 2 hours in PBS at $4{ }^{\circ} \mathrm{C}$. Before the SEM analyses, brief washing with PBS with three times were performed, followed by dehydrating with ethanol series incubation (70-80-90-100\%, each for 3-5 min). After the dehydration process, critical point drying was performed and scaffolds were coated with thin layer of platinum was investigate cell morphologies.

\section{Genotoxicity Assay}

The first step was seeding $5 \times 10^{5} \mathrm{MEF}$ into per well in a 24-well plate. The second step was giving the medium that was used in the indirect cytotoxicity assay to the test group cells. The standard medium was used for the control group. Test and control groups incubated with their media for 5 days.

After the incubation process, cells were harvested and DNA isolations were obtained. In the last step; isolated DNAs were loaded in the agarose gel electrophoresis for the investigation of DNA fragmentation (15).

\section{Statistics}

Statistical analysis was carried out with SPSS (Version 21.0 for MS Windows, SPSS Inc, Chicago, IL). The One-way ANOVA and Tukey's Multiple Comparison Test were performed to determine significant differences for cell viability tests. The lowest $p<0.05$ was considered statistically significant.

\section{RESULTS and DISCUSSION}

\section{Characterization of the Porosity of PVA-CHI Scaffolds}

Scaffold characterization studies consist of collecting information that might elucidate how the scaffold will perform under different conditions. In this matter, techniques such as FTIR, SEM, swelling, and degradation profile and mechanic analyses will provide the characterization properties of scaffolds. In other words, the results of these tests will provide sufficient and relevant information about how the scaffold behaves and how the scaffold might interact with the surrounding.

In the first part of characterization studies, the samples were analyzed by FTIR to identify the chemical groups of PVA-CHI scaffolds and the results were compared with each other (Figure 1 ). The characteristic absorption peaks of PVA at 858 $\mathrm{cm}^{-1}$ and $1440 \mathrm{~cm}^{-1}$ were seen in the three spectra. In addition, the peak at $1325 \mathrm{~cm}^{-1}$, which is characteristic of chitosan reported as III peaks (23). The peak located at the center of $3500-3000 \mathrm{~cm}^{-1}$ for PVA-CHI scaffolds is corresponding to the overlapped stretching of the hydrogen bond between $-\mathrm{OH}$ and $-\mathrm{NH}_{2}$ (24). The similar FTIR spectra results of a glutaraldehyde cross-linked PVA - CHI scaffolds were also reported by Hu et al. (25).

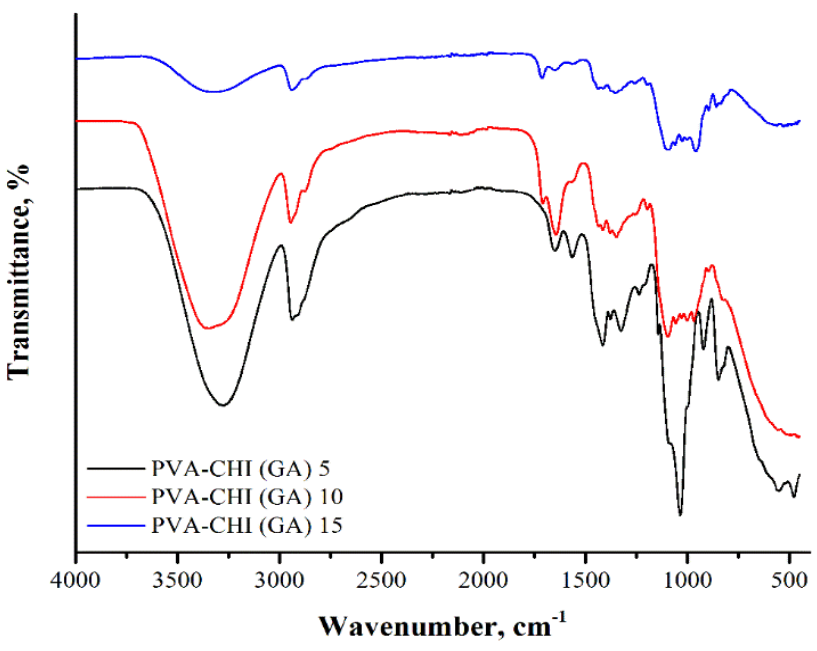

Figure 1. FTIR spectrum of PVA-CHI (GA) 5, PVA-CHI (GA) 10, PVA-CHI (GA) 15 scaffolds.

Figure 2 shows SEM images at cross section of scaffolds with different amounts of GA. For the PVA$\mathrm{CHI}$ (GA) 5 and PVA-CHI (GA) 15 homogeneous pore size distribution is obtained, which occurs at all the areas of cross section, but at the sample PVA$\mathrm{CHI}$ (GA) 10 pore size distribution is not uniform in all the areas. Small pores of PVA-CHI (GA) 10 scaffold aggregate at most while bigger pores are found irregularly among them. In addition, SEM images of the PVA-CHI (GA) 5 scaffold showed more open and interconnected pore morphologies than the PVA-CHI scaffolds. 

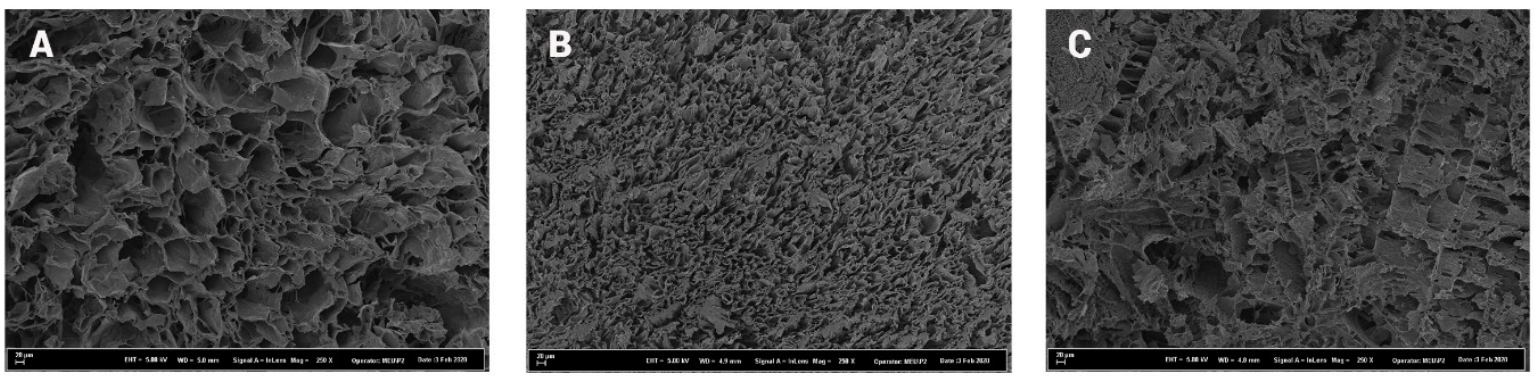

Figure 2. SEM photographs of PVA-CHI (GA) 5, PVA-CHI (GA) 10, PVA-CHI (GA) 15 scaffold (250x).

The swelling ratio or water absorption capacity is closely related to the porosity of biomaterial. As a result of a porous network, proper nutrition process and cell signaling can be achieved in scaffolds (26). The swelling ratio of PVA-CHI scaffolds is shown in Figure $3(A)$. The swelling ratio of PVA-CHI (GA) 5, PVA-CHI (GA) 10 and PVA-CHI (GA) 15 gels are $2000.3 \%, 654.4 \%$, and $1468.04 \%$, respectively. This result indicated that the water absorption capacity of PVA-CHI cryogels changed depending on the crosslinking amount in spite of using PVA and $\mathrm{CHI}$ solutions with fixed concentrations. This significant difference in swelling ratio is due to the basic difference in their pore morphology and wall thickness. Although the PVA-CHI (GA) 10 cryogels consist of a porous structure (the pore size is rather small), PVA-CHI (GA) 5 cryogels have pores that are

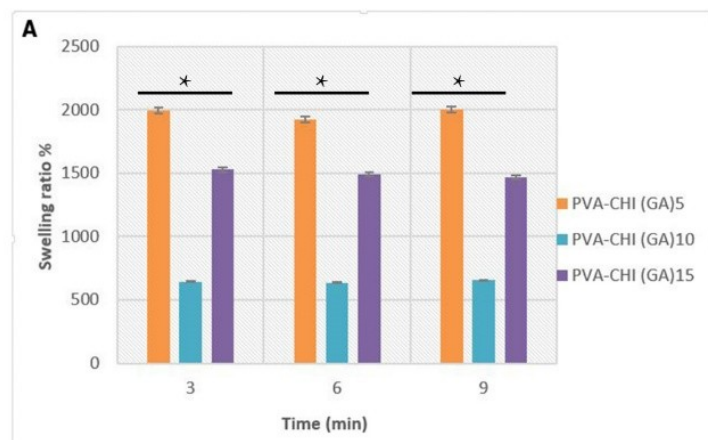

quite large and are interconnected through thin walls. This thin walls allows fast transport of water molecules within thin walls over short distances across the macroporous structure. In addition, pores of PVA-CHI (GA) 10 cryogels were close and were not interconnected. In addition, Figure 3(B) confirmed that the three scaffolds degraded at different rates. PVA-CHI (GA) 15 had significantly decreased by 3 days $(57 \% \pm 2)$ and decreased to $63 \% \pm 1$ by 9 days. PVA-CHI (GA) 5 degradation was slower than PVA-CHI (GA) 10 and PVA-CHI (GA) 15 scaffolds. In addition, as a result of 9 days incubation time the weight loss of PVA-CHI cryogels was increased regularly. The initial degradation ratio of scaffolds may have contributed to the wider pore size and high swelling ratio.

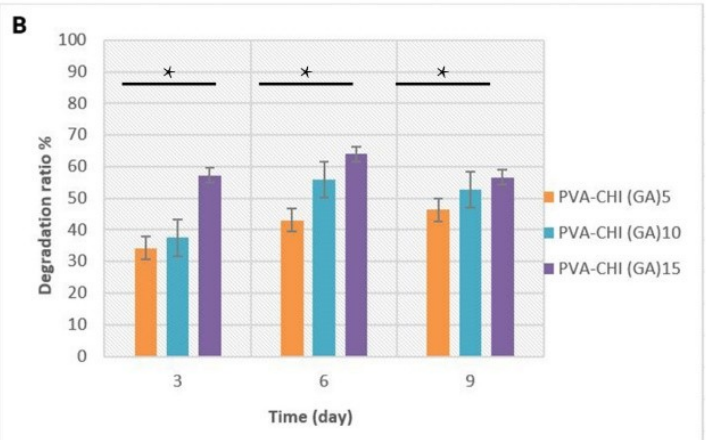
Figure 3. A) Swelling ratio of PVA-CHI cryogels and B) Degradation ratio of PVA-CHI cryogels. Here,
asterisk $(*)$ indicates significant statistical difference ( $p \leq 0.05$, compared between cryogels).

The mechanical tests of PVA-CHI scaffolds were performed under compression in dry conditions and the results of the analysis are presented in Table 2. Compressive strength and young modulus of scaffolds were evaluated. The compressive strength of PVA-CHI (GA) 5 was measured as $128 \pm 10 \mathrm{kPa}$ with $8 \pm 1 \%$ young modulus. The compression strength of PVA-CHI (GA) 5, PVA-CHI (GA) 10 and PVA-CHI (GA) 15 scaffolds were determined as $128 \pm 10,150 \pm 13$ and $150 \pm 13 \mathrm{kPa}$ under dry conditions, respectively. In the view of literature research, the young's modulus of the scaffolds was on the level of smooth muscle and demineralized bone (27). 
Table 2. Mechanical properties of cryogels.

\begin{tabular}{|l|l|l|}
\hline Sample & $\begin{array}{l}\text { Compression } \\
\text { strength, kPa }\end{array}$ & $\begin{array}{l}\text { Young } \\
\text { modulus, } \\
\mathbf{k P a} / \%\end{array}$ \\
\hline PVA-CHI (GA) 5 & $128 \pm 10$ & $8 \pm 1$ \\
\hline PVA-CHI (GA) 10 & $150 \pm 13$ & $9 \pm 5$ \\
\hline PVA-CHI (GA) 15 & $647 \pm 51$ & $43 \pm 3$ \\
\hline
\end{tabular}

\section{Cytotoxicity Studies}

The amount of GA resulted difference in characteristic properties of scaffolds such as mean pore size, degradation, and swelling ratio. In addition to pore size properties, mechanical results show that compression strength and young modulus value of PVA-CHI based cryogels are changing with the crosslinking amount. PVA-CHI (GA) 5 formulated scaffold has uniform pore size distribution for cell interactions and mass or oxygen transportation. Mechanic properties were also acceptable for different tissue engineering applications. In the light

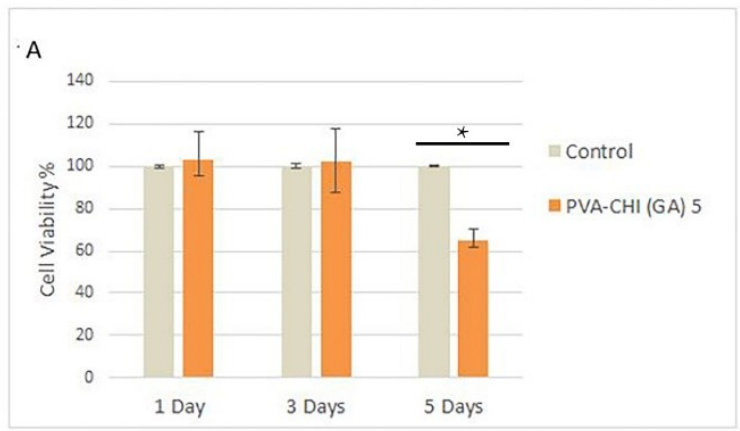

of characterization results, PVA-CHI (GA) 5 was chosen for future studies and cytotoxicity analysis was studied for this cryogel.

The MEF cells were treated with PVA-CHI (GA) 5 cryogel for 1,3 , and 5 days for direct and indirect tests. MTT assay was utilized to analyze the cell proliferation rates for PVA-CHI (GA) 5 cryogel scaffolds at the end of the incubation times. Figure 4(A) and 4(B) show the direct and indirect cell viability rate of MEF cells, respectively.

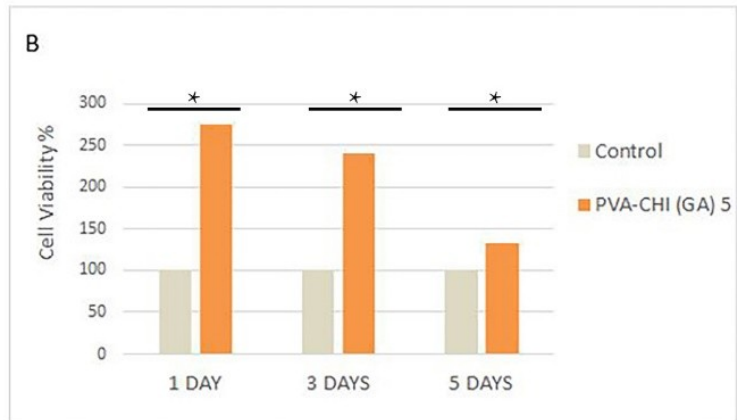

Figure 4. Evaluation graph of cytotoxicity potential of the PVA-CHI (GA) 5 cryogels ; A) direct test results, $B)$ indirect test results. Here, asterisk $\left(^{*}\right)$ indicates significant statistical difference ( $p \leq 0.05$, compared between control and cryogels).

It was determined that PVA-CHI (GA) 5 caused a slight decrease in MEF cell viability in the direct test $(103.19 \% \pm 3.30 \%)$, except 5 days of incubation. The reason for this may be explained, based on the limiting area of the scaffold at the end of the 5 days incubation time. On the other hand, PVA-CHI (GA) 5 formulation significantly induced cell proliferation rate for indirect tests compared to control cells.

For the indirect test, cell viability percentage for PVA-CHI (GA) 5 scaffold decreased when the culture time increased from 1 to 5 days $(274.33 \% \pm 4.40 \%$ to $133.21 \% \pm 4.40 \%)$. This result can be contributed to the limitation of area for cell proliferation and growth.
Different research studies show that PVA - CHI based scaffolds have high blood compatibility and are good candidates for the use as matrices for tissue engineering applications (28). Alhosseini et al. evaluated the physicochemical, structural and physicochemical properties of PVA - CHI electrospun fibers and reported that PVA - CHI electrospun fibers enhance the viability and proliferation of PC12 neural cells. In addition, Peng et al. produced PVA $\mathrm{CHI}$ hydrogels and combined with mesenchymal stem cells to analyze its application in articular cartilage repair and reported positive effects of PVA - CHI scaffold on cartilage healing (28). 

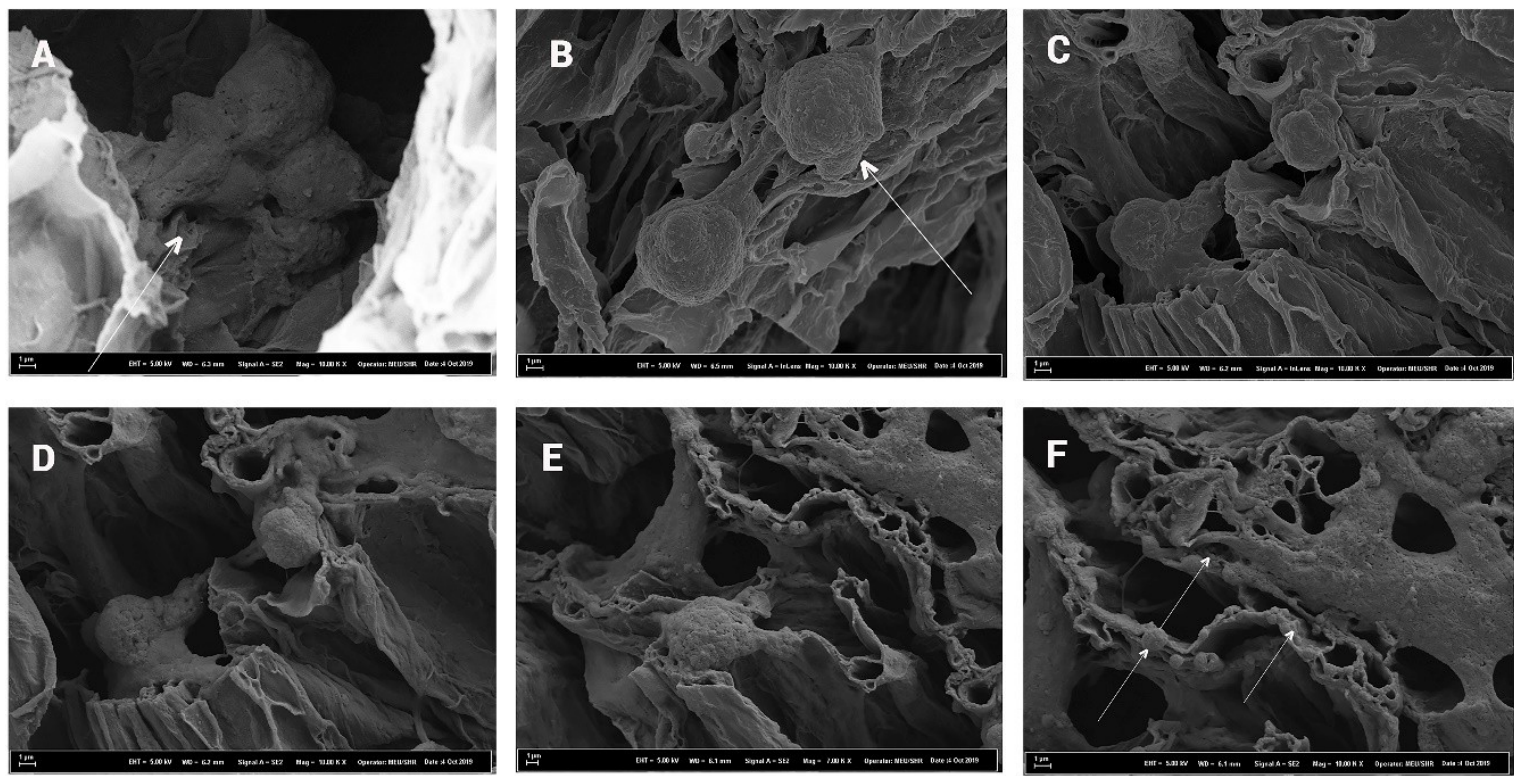

Figure 5. SEM photographs of MEF cells, cultured for 5 days on PVA-CHI (GA) 5 scaffold.

In addition to the cytotoxicity test, Figure 5 presents the SEM images of MEF cells cultured for 5 days on PVA-CHI (GA) 5 scaffold. It can be seen that MEF cells adhered well on the surface of all the scaffolds. Most of the cells on PVA-CHI (GA) 5 scaffolds were observed in normal morphology (Figure 5 A-D). On the other hand, a small number of blebbings and round-shaped cells were present on the scaffolds. Also, elongated spindle-like morphology of MEF cells can be seen on PVA-CHI (GA) 5 scaffolds in SEM photographs (Figures 5 D). Figure $5 \mathrm{~F}$ among the SEM figures, shows the cells are piled up and to provide better cell proliferation. This figure also presents extracellular matrix formation beginning on the scaffold.

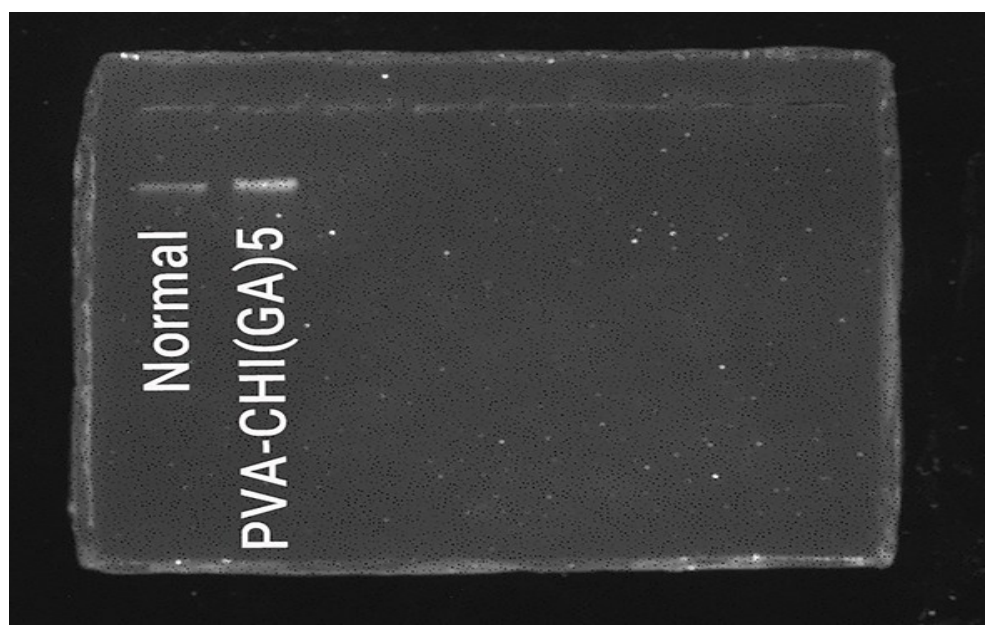

Figure 6. Genotoxicity tests results of the control group and PVA-CHI (GA) 5 scaffold (agarose gel electrophoresis, first line: control group DNA, second line: scaffold group DNA).

Results of the genotoxicity assay of control and PVA-CHI (GA) 5 scaffold are shown in Figure 6. The agarose gel electrophoresis results show that PVACHI (GA) 5 scaffolds did not create DNA fragmentation. So it can be said that the results of genotoxicity experiments indicate that PVA-CHI (GA) 5 scaffold formulation has no genotoxic potential. Similar observations have been made by Kelly et al. and Lima et al. who investigated a series of PVA and chitosan based materials at different techniques and evidenced PVA-CHI biomaterials have no genotoxic potential $(29,30)$.

\section{CONCLUSION}

PVA-CHI based cryogels were fabricated for different potential tissue engineering applications. In this study, the effects of GA into PVA-CHI based 
scaffolds on physical, mechanical and cell proliferation properties were investigated. The SEM results demonstrated that all prepared cryogels were porous and mechanical strength increased with increasing GA amount. In addition, PVA-CHI (GA) 5 scaffold has a uniform and well-designed interconnected macroporous structure. In the light of characterization properties, PVA-CHI (GA) 5 formulated cryogel chosen for cell studies. In vitro results of cytotoxicity and genotoxicity studies confirmed that PVA-CHI (GA) 5 formulated scaffold has no toxic potential. Additionally, cell morphologies on the scaffold supported the MTT assay cytotoxicity experiment results. These results indicate that PVA-CHI based cryogels have a high potential as biomaterials for tissue engineering.

\section{ACKNOWLEDGEMENT}

This work was supported by the Scientific Research Projects Unit of Adana Alparslan Türkeş Science and Technology University (BAP-20103004).

\section{REFERENCES}

1. Shaltooki M, Dini G, Mehdikhani M. Fabrication of chitosan-coated porous polycaprolactone/strontiumsubstituted bioactive glass nanocomposite scaffold for bone tissue engineering. Mater Sci Eng $C$ [Internet]. 2019;105(May):110138. Available from: https://doi.org/10.1016/j.msec.2019.110138

2. Marsich E, Bellomo F, Turco G, Travan A, Donati I, Paoletti S. Nano-composite scaffolds for bone tissue engineering containing silver nanoparticles: preparation, characterization and biological properties. J Mater Sci Mater Med. 2013;24(7):1799-807.

3. Mani MP, Jaganathan SK, Prabhakaran $P$, Nageswaran G, Krishnasamy NP. Electrospun polyurethane patch in combination with cedarwood and cobalt nitrate for cardiac applications. J Appl Polym Sci. 2019;136(47):48226.

4. Hutmacher DW. Scaffolds in tissue engineering bone and cartilage. 2000;21:2529-43.

5. Salgado AJ, Coutinho OP, Reis RL. Bone tissue engineering: State of the art and future trends. Macromol Biosci. 2004;4(8):743-65.

6. Lu DR, Xiao CM, Xu SJ. Starch-based completely biodegradable polymer materials. Express Polym Lett. 2009;3(6):366-75.

7. Hsieh WC, Liau JJ. Cell culture and characterization of cross-linked poly(vinyl alcohol)g-starch 3D scaffold for tissue engineering. Carbohydr Polym [Internet]. 2013;98(1):574-80. Available from: http://dx.doi.org/10.1016/j.carbpol.2013.06.020
8. Gualandi C. Porous Polymeric Bioresorbable Scaffolds for Tissue Engineering. University Of Bologna,Italy; 2011.

9. Kemençe N, Bölgen N. Gelatin- and hydroxyapatite-based cryogels for bone tissue engineering: synthesis, characterization, in vitro and in vivo biocompatibility. J Tissue Eng Regen Med. 2017;11(1):20-33.

10. Pinto R V, Gomes PS, Fernandes MH, Costa ME $\mathrm{V}$, Almeida MM. Glutaraldehyde-crosslinking chitosan scaffolds reinforced with calcium phosphate spray-dried granules for bone tissue applications. Mater Sci Eng C. 2020;109:110557.

11. Mohammadzadehmoghadam S, Dong $\mathrm{Y}$. Fabrication and characterization of electrospun silk fibroin/gelatin scaffolds crosslinked with glutaraldehyde vapor. Front Mater. 2019;6:91.

12. Ruijgrok JM, De Wijn JR, Boon ME. Optimizing glutaraldehyde crosslinking of collagen: effects of time, temperature and concentration as measured by shrinkage temperature. J Mater Sci Mater Med. 1994;5(2):80-7.

13. Yar M, Gigliobianco G, Shahzadi L, Dew L, Siddiqi SA, Khan AF, et al. Production of chitosan PVA PCL hydrogels to bind heparin and induce angiogenesis. Int J Polym Mater Polym Biomater. 2016;65(9):466-76.

14. Vrana NE, Cahill PA, McGuinness GB. Endothelialization of PVA/gelatin cryogels for vascular tissue engineering: Effect of disturbed shear stress conditions. J Biomed Mater Res - Part A. $2010 ; 94(4): 1080-90$.

15. Ceylan S, Göktürk D, Demir D, Damla Özdemir $M$, Bölgen N. Comparison of additive effects on the PVA/starch cryogels: Synthesis, characterization, cytotoxicity, and genotoxicity studies. Int J Polym Mater Polym Biomater. 2017;1-10.

16. Chhatri A, Bajpai J, Bajpai AK. Designing polysaccharide-based antibacterial biomaterials for wound healing applications. Biomatter. 2011;1(2):189-97.

17. Zargar V, Asghari M, Dashti A. A Review on Chitin and Chitosan Polymers: Structure, Chemistry, Solubility, Derivatives, and Applications. ChemBioEng Rev [Internet]. 2015;2(3):204-26. Available from:

http://doi.wiley.com/10.1002/cben.201400025

18. Râpă $M$, Grosu E, Stoica $P$, Andreica $M$, Hetvary M. Journal of Environmental Research and Protection Polyvinyl alcohol and starch blends: properties and biodegradation behavior. J Environ 
Res Prot. 2014;11(1):34.

19. Gomes ME, Ribeiro AS, Malafaya PB, Reis RL, Cunha AM. A new approach based on injection moulding to produce biodegradable starch-based polymeric sca! olds: morphology, mechanical and degradation behaviour. Biomaterials. 2001;22.

20. Silva GA, Coutinho OP, Ducheyne P, Shapiro IM, Reis RL. The effect of starch and starch-bioactive glass composite microparticles on the adhesion and expression of the osteoblastic phenotype of a bone cell line. Biomaterials. 2007;28(2):326-34.

21. Ozmen MM, Dinu MV, Dragan ES, Okay O. Preparation of macroporous acrylamide-based hydrogels: Cryogelation under isothermal conditions. J Macromol Sci Part A Pure Appl Chem. 2007;44(11):1195-202.

22. Syverud K, Pettersen SR, Draget K, ChingaCarrasco G. Controlling the elastic modulus of cellulose nanofibril hydrogels-scaffolds with potential in tissue engineering. Cellulose. $2015 ; 22(1): 473-81$.

23. Uslu I, Atakol O, Aksu ML. Preparation of PVA / Chitosan Doped with Boron Composite Fibers and Their Characterization. Hacettepe J Biol Chem [Internet]. 2008;36(2):117-22. Available from: http://www.hjbc. hacettepe.edu.tr/article/36/2/117 $\% 5 C n h t t p: / / g a z i . a c a d e m i a . e d u / i b r a h i m U S L U$

24. Liang S, Liu L, Huang Q, Yam KL. Preparation of single or double-network chitosan/poly(vinyl alcohol) gel films through selectiv0ely cross-linking method. Carbohydr Polym [Internet]. 2009;77(4):718-24. Available from: http://dx.doi.org/10.1016/j.carbpol.2009.02.007

25. Hu $\mathrm{H}, \mathrm{Hu} H$, Xin JH, Chan $A$, He L. Glutaraldehyde-chitosan and poly (vinyl alcohol) blends, and fluorescence of their nano-silica composite films. Carbohydr Polym [Internet]. 2013;91(1):305-13. Available from: http://dx.doi.org/10.1016/j.carbpol.2012.08.038

26. Mi Zo S, Singh D, Kumar A, Cho YW, Oh TH, Han SS. Chitosan-hydroxyapatite macroporous matrix for bone tissue engineering. Curr Sci. 2012;1438-46.

27. Reilly GC, Engler AJ. Intrinsic extracellular matrix properties regulate stem cell differentiation. J Biomech [Internet]. 2010;43(1):55-62. Available from:

http://dx.doi.org/10.1016/j.jbiomech.2009.09.009

28. Peng L, Zhou Y, Lu W, Zhu W, Li Y, Chen K, et al. Characterization of a novel polyvinyl alcohol/chitosan porous hydrogel combined with bone marrow mesenchymal stem cells and its application in articular cartilage repair. BMC Musculoskelet Disord. 2019;20(1):1-12.

29. Kelly CM, DeMerlis CC, Schoneker DR, Borzelleca JF. Subchronic toxicity study in rats and genotoxicity tests with polyvinyl alcohol. Food Chem Toxicol. 2003;41(5):719-27.

30. De Lima R, Feitosa L, Pereira A do ES, De Moura MR, Aouada FA, Mattoso LHC, et al. Evaluation of the genotoxicity of chitosan nanoparticles for use in food packaging films. J Food Sci. 2010;75(6). 
